\title{
Roles of Rho-associated kinase in lung cancer (Review)
}

\author{
MUHAMMAD ASYAARI ZAKARIA ${ }^{1}$, NOR FADILAH RAJAB ${ }^{2}$, ENG WEE CHUA ${ }^{3}$, \\ GAYATHRI THEVI SELVARAJAH ${ }^{4}$ and SITI FATHIAH MASRE ${ }^{1}$
}

\author{
${ }^{1}$ Biomedical Science Programme, Centre for Toxicology and Health Risk Studies; \\ ${ }^{2}$ Centre for Healthy Ageing and Wellness, Faculty of Health Sciences; and ${ }^{3}$ Faculty of Pharmacy, \\ National University of Malaysia, 50300 Kuala Lumpur; ${ }^{4}$ Department of Veterinary Clinical Studies, \\ Faculty of Veterinary Medicine, University Putra Malaysia, 43400 Serdang, Malaysia
}

Received May 21, 2020; Accepted December 16, 2020

DOI: 10.3892/ijo.2020.5164

\begin{abstract}
Lung cancer is one of the most lethal forms of cancer known to man, affecting millions of individuals worldwide. Despite advancements being made in lung cancer treatments, the prognosis of patients with the disease remains poor, particularly among patients with late-stage lung cancer. The elucidation of the signaling pathways involved in lung cancer is a critical approach for the treatment of the disease. Over the past decades, accumulating evidence has revealed that Rho-associated kinase (ROCK) is overexpressed in lung cancer and is associated with tumor growth. The present review discusses recent findings of ROCK signaling in the pathogenesis of lung cancer that were conducted in pre-clinical studies. The significant role of ROCK in cancer cell apoptosis, proliferation, migration, invasion and angiogenesis is discussed. The present review also suggests the use of ROCK as a potential target for the development of lung cancer therapies, as ROCK inhibition can reduce multiple hallmarks of cancer, particularly by decreasing cancer cell migration, which is an initial step of metastasis.
\end{abstract}

\section{Contents}

1. Introduction

2. Literature search

3. Overview of Rho-associated kinase signaling pathway

4. Roles of Rho/ROCK signaling pathway in modulating the behavior of lung cancer

5. ROCK signaling pathway inhibition in lung cancer

6. Other druggable targets of lung cancer

7. Conclusion and future direction

Correspondence to: Dr Siti Fathiah Masre, Biomedical Science Programme, Centre for Toxicology and Health Risk Studies, Faculty of Health Sciences, National University of Malaysia, Jalan Raja Muda Abdul Aziz, 50300 Kuala Lumpur, Malaysia

E-mail: sitifathiah@ukm.edu.my

Key words: Rho-associated kinase, lung cancer, non-small cell lung cancer, inhibition, cancer therapy

\section{Introduction}

Globally, lung cancer is the most prevalent type of cancer, affecting 2.09 million individuals and was responsible for 1.76 million associated deaths in 2018 (1). Smoking is the leading cause of lung cancer, as $86 \%$ of individuals with the disease have a history of smoking (2). Lung cancer can be divided into 2 major types, which are small cell lung cancer (SCLC) and non-small cell lung cancer (NSCLC). NSCLC accounts for $>85 \%$ of all lung cancer cases and can be classified into adenocarcinoma (50\%), lung squamous cell carcinoma (SCC) (30-40\%) and large cell carcinomas (10\%) (3). NSCLC is often diagnosed at a late stage, resulting in poor therapeutic responses and high mortality rates $(4,5)$. The 1-year survival rate for patients with lung cancer is $44 \%$, and the 5-year survival rate is only 17\% (6). The treatment options for lung cancer are surgery, radiotherapy, platinum-based chemotherapy and neoadjuvant chemotherapy. However, the efficacy of these treatments for some patients remains unsatisfactory, as lung cancer is a heterogeneous disease. Moreover, these treatments can have deleterious side-effects, while patients with metastatic tumors are vulnerable to developing a post-treatment resistance to such medications, rendering the treatment of lung cancer difficult (7). However, improvements in effectiveness and survival rates have been observed when histology-guided chemotherapy, maintenance therapy, or vascular endothelial growth factor (VEGF)-targeted therapy is combined with platinum doublet therapy, which is the standard therapy for unresectable and metastatic lung cancer $(8,9)$. Nowadays, novel therapies targeting molecular aberrations or driver mutations have emerged as a therapy of choice due to the excellent effectiveness and lower side-effects, owing to the completely sequenced human genome allowing the identification of novel mutations that play a key role in lung carcinogenesis. An example of such a therapy, which has been tested and has yielded promising results, is tyrosine kinase therapy, that specifically targets the epidermal growth factor receptor (EGFR), a type of protein commonly altered in NSCLC (10). However, this novel treatment spectrum only includes a minority of patients that harbor the mutation (11). Therefore, targeting oncogenic pathways that play a central role in cancer is a sensible strategy, as it is likely to be effective. One such pathway that has recently become of interest 
in cancer therapy is the Rho-associated kinase signaling pathway (ROCK).

ROCK plays an essential role in carcinogenesis, particularly in promoting cancer cell motility that causes metastasis. ROCK is an effector of the small GTPase Rho and has been studied in various malignancies, such as breast (12), skin (13), liver (14) and lung cancer (15). Studies on lung cancer usually use NSCLC cell lines or tissue biopsies from patients with NSCLC to assess changes in the proliferation, migration, and growth of cancer following the inhibition of knockdown of ROCK (16-21). These studies have found that ROCK is responsible for promoting lung cancer growth if upregulated or overexpressed, and this has led researchers to suggest that ROCK may be a novel target for the treatment of lung cancer.

In the present review, the role of ROCK in lung cancer is discussed and the published evidence from in vitro and in vivo studies that were performed to decode the function of ROCK in lung cancer is summarized.

\section{Literature search}

A literature search on ROCK and studies on lung cancer was conducted from January 1, 2020, to November 15, 2020 using Scopus, PubMed and Web of Science, with the following keywords: 'ROCK OR Rho' OR 'Rho-associated kinase' AND 'Lung cancer' OR 'NSCLC' OR 'Non-small cell lung cancer' OR 'SCLC' OR ‘small-cell lung cancer'. Only original research articles on the roles of ROCK and ROCK inhibition in studies on lung cancer written in the English language were selected for reading. The full text of the articles concerned was retrieved following the screening of the titles and abstracts.

\section{Overview of Rho-associated kinase signaling pathway}

ROCK is a member of the protein kinase A/protein kinase $\mathrm{G} /$ protein kinase $\mathrm{C}$ (AGC) serine/threonine kinases family that plays an essential role in promoting cell motility by facilitating cytoskeleton contractility $(22,23)$. As shown in Fig. 1, ROCK is activated by binding of the Rho GTPase (i.e., RhoA and RhoC) to its Rho-binding domain (RBD), which leads to the activation by phosphorylation of the myosin-binding subunit of the myosin light chain phosphatase (MYPT) (24), myosin light chain (MLC) (24) and LIM kinases (LIMK) $(25,26)$. The activation of the MLC substrate leads to the activation of myosin II motor activity, leading to the crosslinking of myosin to filamentous actin (F-actin), enhancing actomyosin cytoskeleton contractility $(27,28)$. On the other hand, the activation of MYPT inhibits MLC dephosphorylation, and the activation of LIMK phosphorylates cofilin, which renders it inactive and unable to polymerize F-actin (29). In brief, the phosphorylation of MLC and MYPT leads to increased levels of phospho-MLC, and thus promotes actomyosin contractility, which alters the migratory behavior of cells. Enhanced contractility resulting from ROCK activation also facilitates cancer cell proliferation and regulates cell adhesion (28,30-32).

There are 2 ROCK homologs, namely ROCK1 and ROCK2. Collectively they are referred to as ROCK. ROCK1 and ROCK 2 consist of 1,354 and 1,388 amino acids, respectively, and both contain an N-terminally located kinase domain, a coiled-coil region followed by a Rho-binding domain (33).
The homologs share $\sim 65 \%$ similarity in their overall amino acid sequences, and the sequence similarity increases to $92 \%$ if only their kinase domains are compared (22). Although both ROCK proteins share the same function, which is to regulate cytoskeleton contractility and exert a redundant effect on MLC and MYPT phosphorylation (34), they have also been found to differ from each other in terms of tissue distribution and subcellular localization. ROCK1 is ubiquitously expressed in non-neuronal tissues such as the lungs, liver, thymus, stomach, spleen, kidneys, testes, placenta and embryo $(22,28)$. ROCK1 has been found at the microtubule-organizing center, cytoplasm, plasma membrane, and cell-cell adhesion sites $(19,35,36)$. Moreover, ROCK2 is abundant in the brain, muscle, placenta, lungs and heart $(22,28)$. It has been found to be localized at the nuclei and pre-synapses, including active zones (31). Notably, different types of cancer seem to have various needs for the ROCK proteins, specifically expressing both ROCK1 and ROCK2, or either alone (37-40). According to Kümper et al (34), both ROCK isoforms are independently important to the cells since the cells that lack any of the ROCK isoforms are still capable of proliferating. However, the cells that lack both ROCK isoforms are unable to contract and become flattened out. Eventually, cell division and growth are attenuated. This evidence has demonstrated the essential role of ROCK in maintaining cell survival, and the heterogeneity of ROCK expression in different types of cancer has particularly suggested the need for the development of a ROCK isoform-specific cancer therapy.

ROCK signaling pathway and expression in lung cancer. ROCK activation is positively associated with tumor growth (13,41-43), and a growing number of studies continue to lend credence to the importance of the ROCK signaling pathway in lung cancer development. ROCK is one of the Rho pathway genes that is significantly upregulated in a number of KRAS mutant NSCLC cell lines $(44,45)$, several NSCLC animal models $(15,46)$, and tumor tissues derived from patients with NSCLC $(37,47)$. Furthermore, ROCK is also upregulated in bronchial epithelial cell lines exposed to cigarette smoke (48) and even in the lungs of smokers (49). This high expression of ROCK in NSCLC cells and tissues indicates that ROCK plays an important role in the initiation of the development of NSCLC, as shown by ROCK inhibition and knockdown studies, which will be addressed below. The expression levels of the ROCK upstream effector, RhoA, and ROCK downstream substrates, MYL9 or MLC, have been found to be higher in late-stage (stage II and IV) compared with early-stage (stage I and II) lung cancer $(50,51)$. ROCK1 and MLC expression levels have also been found to be higher in NSCLC with lymphatic metastasis than in NSCLC without lymphatic metastasis $(19,37,50)$. According to $\mathrm{Hu}$ et al (37), ROCK1 expression has a significant positive association with tumor size and clinical stage, as measured in NSCLC tissues collected from the clinical setting. Moreover, a high ROCK1 expression has also been found to be associated with poor survival rates of patients with NSCLC. To support the findings of ROCK1 expression, Du et al (19) performed immunohistochemistry (IHC) on 10 NSCLC tissues with lymph node metastasis, which revealed a higher ROCK1 expression in 6 out of 10 tissues. However, IHC-screened 


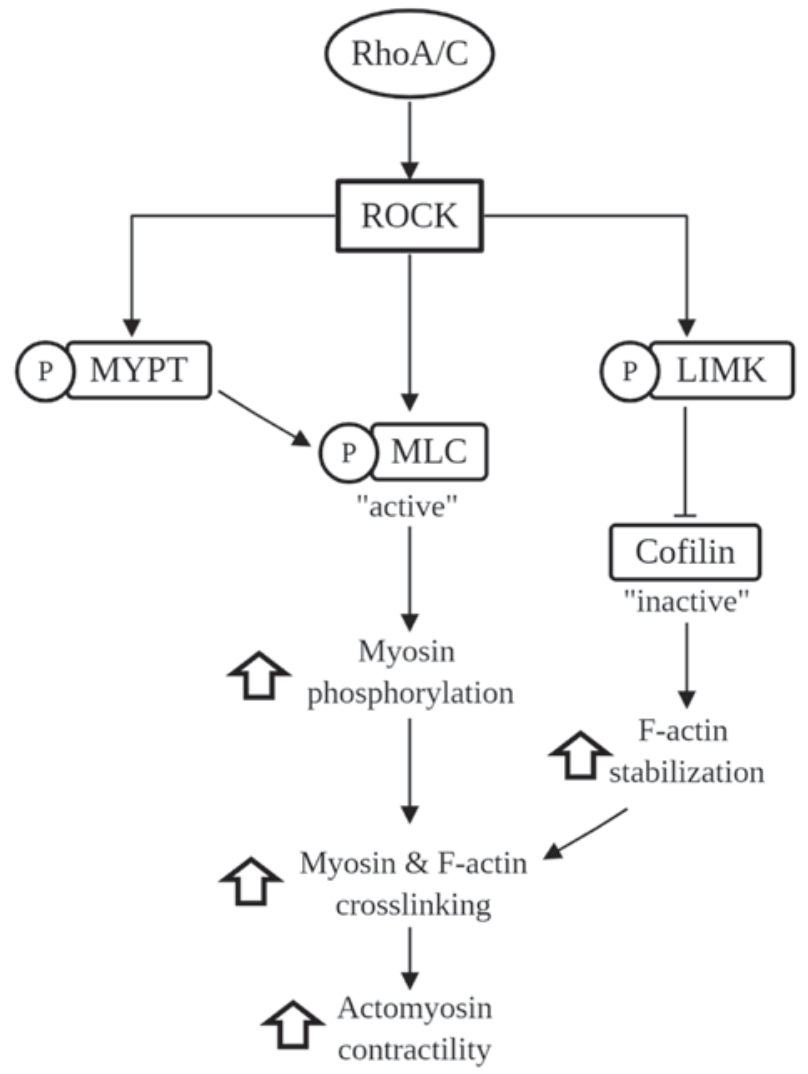

Figure 1. Overview of the ROCK signaling pathway. ROCK, Rho-associated kinase; MYPT, myosin light chain phosphatase; MLC, myosin light chain; LIMK, Lim kinase.

ROCK1 expression in NSCLC tissues without lymph node metastasis was only higher in 2 out of 10 tissues.

Factors potentiating the ROCK signaling pathway in lung cancer. The increased stiffness of the extracellular matrix (ECM) in a tumor is one of the factors recognized to activate Rho GTPases, as demonstrated in a 3D culture system with varying levels of tissue or substrate stiffness $(12,52)$. The aim of this ROCK activation is to counterbalance the external force exerted on cells by increasing the contractility of the internal cytoskeletal structure (53). The increased stiffness of lung cancer is promoted by the increased production of cancer-associated fibroblasts and various ECM proteins, such as fibrillary collagen, fibronectin and tenascin C (54). Collagen, the main component of the ECM, has been shown to increase tensile strength in lung cancer and to interact with fibroblasts to activate ROCK (55). ROCK is activated by physical changes via the $\beta$-integrin receptor, a transmembrane protein (56), which phosphorylates focal adhesion kinase (FAK) (57). Activated FAK or p-FAK subsequently activate the downstream substrates, RhoGTPase and ROCK (58). Apart from increased tissue stiffness, tumor tissue also develops hypoxic regions with known partial oxygen pressure in lung cancer of only $16.6 \mathrm{mmHg}$ (59) and it has been demonstrated that this condition can increase the expression of RhoA/ROCK in lung cancer (60). Cancer cells in hypoxic tumors are usually deprived of oxygen, which causes them to migrate to less hypoxic microenvironments through hypoxia-inducible factors (HIFs) and to later transactivate RhoA/ROCK.
Since ROCK is a key protein that promotes cell motility, its upregulation in the hypoxic condition is crucial (61). During the process, cancer cells can escape the basement barrier and gain access to circulation through tumor vasculature by intravasation, which is the first step of metastasis (62). Collectively, this evidence indicates that both increased tissue stiffness and the hypoxic environment of a tumor may lead to the ROCK-mediated malignant transformation of lung cancer, indicating the important role of these biophysical properties in the promotion of carcinogenesis.

\section{Roles of Rho/ROCK signaling pathway in modulating the behavior of lung cancer}

Cancer cell apoptosis. The ROCK signaling pathway plays multiple roles in lung cancer carcinogenesis, including the suppression of apoptosis and conferring immortality to cancer cells (30). ROCK activation inhibits caspase-3, a crucial mediator of apoptosis, which eventually suppresses MYC-induced apoptosis $(63,64)$. The reduction of caspase-3 has been suggested to inhibit the cell cycle, thereby providing a path for NSCLC to bypass senescence (65). The effect of ROCK on apoptosis via caspase-3 regulation was confirmed by Yang et al (66) who reported an increased level of active caspase-3 in a SCLC cell line following treatment with fasudil, a ROCK inhibitor. In addition, a previous study by Xin et al (67) reported that NSCLC cells treated with small interfering RNA (siRNA) against ROCK1 or ROCK1 knockdown resulted in apoptosis induced by the upregulation of the LATS2 and JNK signaling pathway, suggesting the functional role of ROCK in the regulation of lung cancer apoptosis. Another mechanism of the suppression of apoptosis is through the increment of phospho-signal transducer and activator of transcription 3 (p-STAT3) (64) and nuclear factor $-\kappa \mathrm{B}(\mathrm{NF}-\kappa \mathrm{B})(68)$, which both are initially activated by RhoA (69). STAT3 upregulation can upregulate its downstream target responsible for the suppression pf apoptosis, such as c-MYC, cyclin D1 and survivin (70). However, NF- $\kappa$ B plays a critical role in desensitizing cells to apoptosis by suppressing reactive oxygen species (ROS) and antagonizing p53 (68). According to $\mathrm{Gu}$ et al (71), NF- $\kappa \mathrm{B}$ expression was found to be highly expressed and associated with poor survival outcomes among patients with NSCLC, suggesting the essential role of $\mathrm{NF}-\kappa \mathrm{B}$ in driving carcinogenesis. In conclusion, the ROCK signaling pathway is capable of promoting the survival and growth of lung cancer cells by suppressing apoptosis and bypassing senescence through multiple mechanisms.

Cancer cell proliferation. The regulation of cell proliferation is another prerequisite for the development of lung cancer other than apoptosis (72). RhoA/ROCK has been shown to play an important role in promoting the proliferation of NSCLC in in vitro (20,73-75) and in vivo (34) studies. The majority of these studies used MTT or MTS tetrazolium assays to measure the level of cell proliferation. In ROCK-activated fibroblasts, Ras/MAPK increased the expression of multiple downstream signaling cascades, such as p27, cyclin D1 and cyclin A (76), which are known to promote cell cycle progression and cell proliferation (77). Notably, ROCK knockdown results in the downregulation of cyclin D1 and cyclin E in NSCLC cells (67), 
suggesting the functional role of ROCK in promoting cell proliferation if overexpressed. In addition, other studies have also attempted to elucidate the role of ROCK in promoting cancer cell proliferation by using ROCK inhibitors or knockdown of ROCK. The studies by Liu et al (64) and Tang et al (78) demonstrated that the application of RhoA inhibitor and RhoE/rnd3 (RhoA competitor) was capable of inhibiting ROCK activation, thus reducing the proliferation of lung cancer cells. Of note, the study by Kümper et al (34) using NSCLC cells and animal models found that the depletion of both ROCKs led to a cell proliferation defect by affecting MLC and MYPT phosphorylation. However, the proliferation defect was not observed in NSCLC cells lacking either ROCK 1 or ROCK2, demonstrating the functional role of both ROCK isoforms in cell proliferation. Thus, these studies indicated that ROCK activated multiple proteins that play a key role in promoting cell proliferation during lung cancer development.

Cancer cell migration. Since cell migration is a pivotal step in metastasis, it is important to identify molecular pathways that promote cancer cell motility or migration. Cancer cell migration is a dynamic process involving several biochemical and morphological changes. ROCK is the most well-known signaling pathway that promotes cancer cell migration as it can regulate cytoskeletal contractility (79). According to $\mathrm{Hu}$ et al (37), ROCK1 has been reported to enhance NSCLC cell migration by inhibiting phosphatase and tensin homolog (PTEN) activation, which then activates the phosphoinositide 3-kinase (PI3K)/AKT and FAK signaling pathways. This hierarchy of events promotes cell migration by increasing cytoskeletal contraction and by regulating cell-cell adhesion. ROCK further promotes the motility of NSCLC cells through the formation of lamellipodia at the edge of the cell surface by increasing pFAK colocalization with actin (37) and by cofilin inactivation (80), resulting in plasma membrane protrusion (81). Cancer cells employ 2 migration phenotypes that ROCK is capable of performing, the amoeboid and mesenchymal phenotype. ROCK is the most prominent signaling pathway that regulates amoeboid migration (82), characterized by losing of cell-cell and cell-ECM adhesion, eventually forming a bleb. The amoeboid type of migration uses a bleb-driven mechanism to pass through the holes in the surrounding 3D network of ECM filaments $(82,83)$. In comparison, the mesenchymal mode of migration induced by the EMT process is characterized by the acquisition of mesenchymal characteristics which causes the loss of intact cell-cell contact and apical-basal polarity. EMT also mediates cytoskeleton contractility, which results in a change in cell shape from a cuboidal to a spindle-like shape that aids cell migration and has been found to be caused by TGF- $\beta 1$ released by RhoC and ROCK activation in lung cancer (19,84-86). Therefore, ROCK is suggested as a worthy target to decrease cell migration since it plays an essential role in regulating the 2 main types of cell migration that aid metastasis.

Cancer cell invasion. Concurrently, cancer cells begin to invade their surroundings as they develop malignant phenotypes, particularly an enhanced cell motility. Invasion processes include extracellular matrix remodeling by matrix metalloproteinases (MMPs), which can degrade the basement membrane and stromal ECM, thereby providing a 'path' for cancer cells to invade (87). In this regard, ROCK has been found to play an essential role in the invasion of NSCLC cells by increasing the MMP-2 and MMP-9 expression (17), which are also known to promote angiogenesis and VEGF production (88). In addition, another family of MMPs, including MMP-10 and MMP-13, has been found to play a key role in the invasion of lung cancer by increasing the vascular permeability that aids in cancer cell intravasation into blood vessels (89). Notably, a high expression of MMPs has been reported in late-stage and metastatic lung cancer compared to early-stage and non-metastatic NSCLC (90). Their expression is also directly associated with the high potential of NSCLC invasion (91). This further supports to the role of ROCK and MMPs in promoting invasion, which will inevitably lead to metastasis.

Angiogenesis. RhoA/ROCK is responsible for the formation of a vascular structure or angiogenesis necessary for the growth of the tumor. The actin cytoskeleton regulated by ROCK plays a central role in the angiogenesis process involving endothelial cells (EC) proliferation, branching and sprouting (92). The study by Zhang et al (81) demonstrated that lung cancer cells that were conditioned with endothelial cells relied on RhoA/ROCK signaling to invade and metastasizes by angiogenesis. ROCK is also involved in the formation of a specific type of vascular pattern in NSCLC known as vasculogenic mimicry (VM), which preferably forms in the hypoxic environment of the tumor $(93,94)$. VM is a supplement to endothelial cell-dependent angiogenesis induced by cancer cells (95). ROCK-induced VM formation is associated with the expression of the glycoprotein dimer known as Semaphorin 4D (Sema4D). Sema4D has been shown to be highly expressed in various types of solid tumors, including lung cancer (96). With respect to the pro-angiogenic factor, ROCK has also been reported to stimulate the secretion of VEGF, which is responsible for vascular formation from cancer cells and infiltrating immune cells. This regulation was reported by Zhu et al (17), who found a decreased VEGF expression in NSCLC cells treated with fasudil. They also reported decreased cell proliferation, migration, invasion and angiogenesis in cells with a low VEGF expression, suggesting the essential role of VEGF in lung cancer carcinogenesis. Similarly, another study by Zahra et al (97) reported decreased endothelial cell proliferation, migration and tube formation that induced angiogenesis following VEGF inhibition by RhoA knockdown. In summary, ROCK, Sema4D and VEGF are good targets for anti-angiogenic therapy as they play an essential role in angiogenesis. In particular, ROCK holds promise for use as a novel anticancer therapy, as it is capable of regulating a number of downstream signaling pathways and factors crucial in carcinogenesis, as shown in Fig. 2.

\section{ROCK signaling pathway inhibition in lung cancer}

Since the use of the first approved ROCK inhibitor (fasudil) for the treatment of cerebral vasospasms (98), immense efforts have been made to repurpose the therapeutic benefits of this agent for the treatment of cancer (81,99-101). Apart from fasudil, a wide range of compounds has also been tested against lung cancer, and as ROCK overexpression or upregulation is associated 


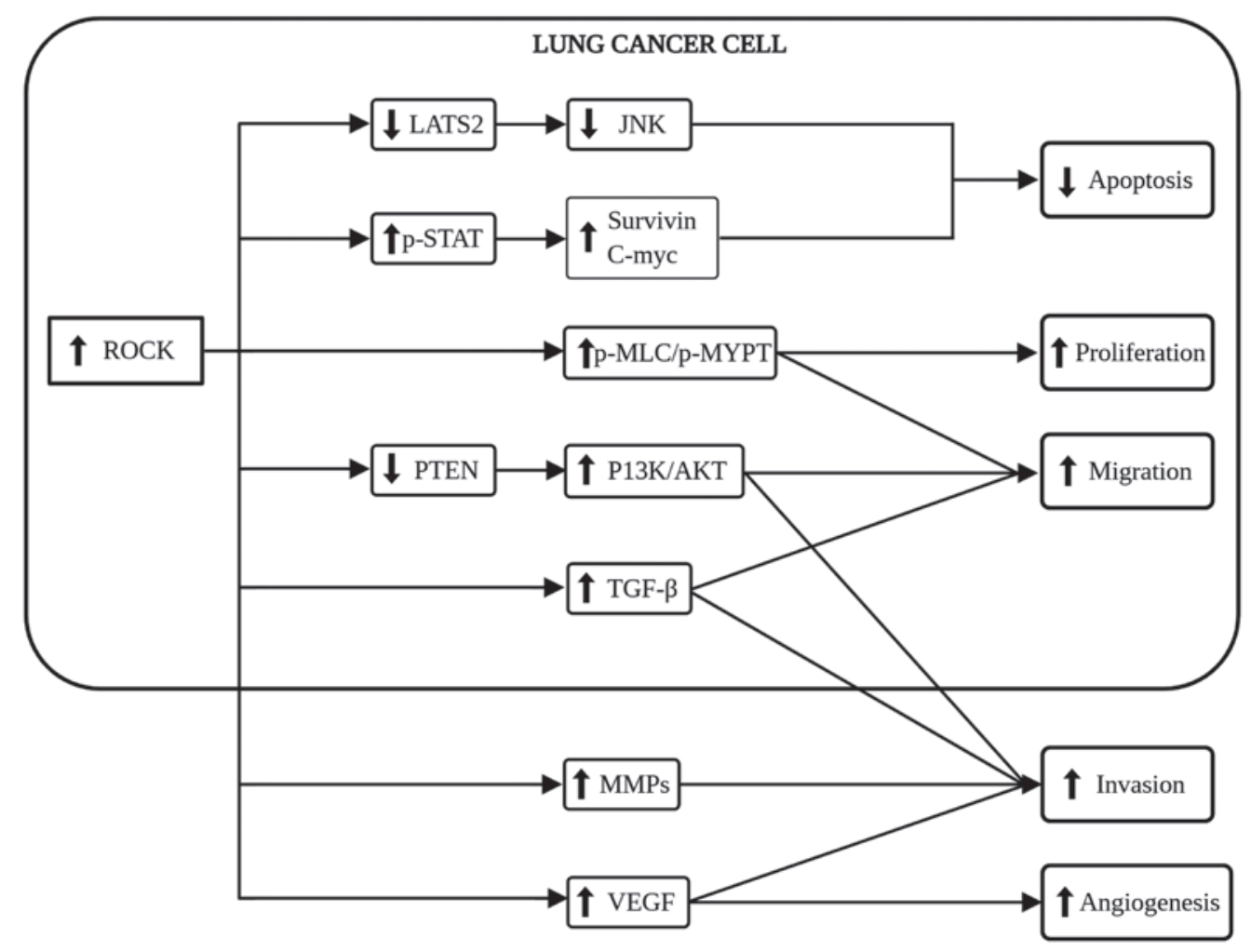

Figure 2. Diagram illustrating the signaling pathways and factors studied to be activated by ROCK in lung carcinogenesis. ROCK, Rho-associated kinase.

with an enhanced growth of lung cancer as discussed above, the current treatment modality is to inhibit or reduce ROCK expression. Researchers have been testing several inhibitors that may target ROCK upstream effectors or downstream substrates in lung cancer, such as RhoA inhibitor (64), RhoC inhibitor $(85,102)$, ROCK pan-inhibitor (Y27632) $(103,104)$ and LIMK inhibitor (BMS-5) (105). As these targets are intertwined in one signaling pathway, the inhibition of RhoA or LIMK, for example, also yields a preferable result, as with the inhibition of ROCK. Thus, the present review also includes studies on ROCK-associated substrate inhibitors instead of only studies on ROCK inhibition. Novel natural compounds have also been tested for their inhibitory action against ROCK in lung cancer, with promising results $(46,80)$. Examples of the natural compounds studied are zerumbone derived from ginger (80), glabridin from licorice (106), plumbagin from chitrak (46), deguelin from cork bush (107), $\beta$-escin from horse chestnut (108), and XAP from Muruwa (102). In recent years, natural compounds have attracted the attention of researchers in developing novel cancer treatment, since they are believed to exert a less toxic effect on normal cells (109). $\beta$-escin (a RhoA/ROCK inhibitor) for instance, has been evaluated to not cause significant body weight loss or histologic cytotoxicity on normal mice after 34 weeks of treatment, which indicates that this natural compound is unable to jeopardize general health (108). As reviewed by Surien et al (110), a number of natural compounds have been proven to be beneficial in the treatment of lung cancer at pre-clinical studies. From the literature search, the present review identified 6 different studies that evaluated ROCK expression following treatment with natural compounds $(46,80,102,106-108)$. Notably, these natural compounds have been documented to be capable of reducing RhoA, RhoC and ROCK expression, all of which promote cell proliferation, migration, invasion and angiogenesis.

The specificity of ROCK inhibition should also be considered, as some ROCK inhibitors, such as Y-27632 have additional off-target inhibitory activity against mitogen- and stress-activated protein kinase 1 (MSK1) (111). Therefore, a more potent and specific ROCK inhibitor should be developed to resolve these issues. Some researchers have begun to investigate this possibility by developing OXA-06, a potent ATP-competitive ROCK inhibitor that is structurally distinct from Y-27632, a ROCK1/2 inhibitor (15) and a Rho-kinase inhibitor (RKI) (112), both of which have been tested and proven to exhibit less in vitro off-target protein kinase inhibitory activity. OXA-06 also has the ability to block anchorage-independent cancer cell growth by causing cell cycle arrest in G0/G1 (15). siRNA and short hairpin RNA (shRNA) have also been used for the inhibition of ROCK activation in lung cancer studies. These short double-strand RNA molecules are a promising therapeutic approach that can be programmed to silence a specific target. Their use, either in vitro or in vivo, has allowed researchers to compare the effects of ROCK inhibition with those of their novel compounds and has enhanced our understanding of the underlying mechanisms that regulate this pathway. For example, siRNA targeting either ROCK1 or ROCK2 alone is capable of inhibiting $\sim 90 \%$ of NSCLC anchorage-independent cells. Moreover, non-specific siRNA that targets both ROCKs effectively inhibits tumor growth as reflected by near-complete colony formation suppression. These findings demonstrate that siRNAs can specifically discriminate against ROCK homologs and give a clear image of their inhibition effects on 
a specific ROCK homolog (15). Moreover, shRNA has been used to target RhoC (85) and ROCK1 (37) in lung cancer studies. These studies reported that the inhibition of RhoC and ROCK1 by shRNA significantly suppressed the EMT process and the migration of lung cancer, as with other ROCK inhibitors.

The use of microRNAs (miRNAs or miRs) for the treatment of lung cancer has also been documented. miRNAs are small, non-protein-coding RNA molecules that have been shown to be involved in carcinogenesis as either tumor suppressors or oncogenes (113). miRNAs are regarded as convenient biomarkers due to their better stability compared to mRNAs. As reviewed by Iqbal et al (114), several miRNAs have been identified to play a prominent role in lung cancer, and a few have been identified to target RhoA/ROCK. Throughout the literature, only 4 studies on miRNAs have been found that elucidate ROCK expression. These miRNAs have been reported to be downregulated in NSCLC tissue biopsies and their restoration in vitro has been reported to reduce the proliferation, migration and invasion of the A549, H1299 and SPC-A1 cell lines by decreasing ROCK expression $(19,20,115,116)$. Furthermore, a previous meta-analysis and Kaplan-Meier data by Yang et al (117) and Wu et al (118) demonstrated that other miRNAs, such as miRNA-21, miRNA-155, miRNA-19b and miRNA-146a, can be used to predict recurrence, as a prognostic biomarker and to demonstrate association with the survival rate of patients with lung cancer.

Generally, studies on ROCK and lung cancer in literature can be divided into 2 major categories: Kinase-targeting ROCK inhibition (Table I) and non-kinase-targeting ROCK inhibition (Table II). Kinase-targeting ROCK inhibitors target upstream effectors, downstream substrates, or ROCK, whereas non-kinase-targeting ROCK inhibitors target signaling pathways other than ROCK, such as proteins, oncogenes and non-coding RNAs, but can still affect ROCK expression. The targets of the 24 ROCK inhibitors identified in the literature are presented in Fig. 3. Collectively, these inhibitors can inhibit MLC/LIMK phosphorylation, which activates cofilin and promotes F-actin depolymerization. As a result, crosslinking between F-actin and myosin is reduced, leading to a decrease in actomyosin contractility, which plays an essential role in the transformation of malignant phenotype in cancer cells (119). It was found that the majority of the kinase-targeting ROCK inhibition studies were conducted in vitro using NSCLC cell lines, while there is a lack of studies conducted in vivo or by using tissue biopsies of lung cancer patients. The most commonly used cell line is human A459 lung adenocarcinoma cells, followed by H1299 and $\mathrm{H} 460$ cells, which are also categorized as NSCLC.

Targeting proteins, oncogenes, or non-coding RNAs that coordinate Rho may also be a promising approach, as presented in non-kinase-targeting ROCK inhibition studies (Table II). Generally, these studies have reported that NSCLC tissue has a higher expression of DEK (73), keratin14 (KRT14) (120), chromodomain helicase DNA-binding protein 4 (CHD4) (74) and long non-coding RNA (lncRNA) NORAD (121); the depletion or disruption of these has been observed to reduce RhoA, ROCK and phospho-myosin expression in NSCLC cell lines. It has also been demonstrated that the depletion of these proto-oncogenes is capable of inhibiting NSCLC cell growth by promoting apoptosis and attenuating their proliferation, migration and invasion $(73,74,120,121)$. In addition, a high DEK and CHD4 expression has been shown to be associated with poor survival rates among patients with NSCLC, as analyzed using Kaplan-Meier data, and to be positively associated with TNM staging, differentiation and nodal status $(73,74)$. Therefore, it is suggested that DEK and CHD4 expression may be critical factors and potential biomarkers of NSCLC progression. Therefore, studies on DEK, CHD4, KRT14 and IncNORAD expression in NSCLC tissues provide insight into the possibility of these proteins to be translated into potential therapeutic targets for treating lung cancer.

Some studies have found inconsistent effectiveness in treating cancer either by targeting both ROCK isoforms, or only one of them. Furthermore, the characterization of the role of ROCK $1 / 2$ in lung cancer carcinogenesis is therefore essential. However, ROCK1 tends to be more significant than ROCK2 in lung cancer studies $(34,37)$. ROCK1 is also the preferred isoform in most of the kinase-targeting ROCK inhibition studies, as shown in Fig. 3. It may be due to the predominant role of ROCK1 over ROCK2 in regulating cytoskeletal organization, which indicates isoform-specific regulation in lung cancer. ROCK1 has been regarded as a positive regulator of cell migration and invasion in several solid tumors, such as osteosarcoma (38), breast (12), pancreatic (122), gastric (123) and lung cancer $(37,124,125)$. In addition, some ROCK inhibitors, such as Y-27632, which can target both ROCK isoforms, have been found to be more potent against ROCK1 than against ROCK2 (126). However, this should not be the reason to discount the role of ROCK2 in lung cancer growth. Further evidence is needed to demarcate the role of ROCK2 in lung cancer. Overall, the aim of these ROCK inhibition studies, either kinase-targeting or non-kinase-targeting ROCK inhibition, is to determine the effects of ROCK inhibition that elucidates the ROCK function in lung carcinogenesis. The majority of the studies included cell migration assays to investigate cellular motility changes following ROCK inhibition or knockdown, since it is a key mediator that regulates cytoskeletal rearrangement that affects cellular motility $(37,104,116,125)$. Examples of the migration assays employed are Transwell, collagen invasion, tube formation and scratch wound healing assays. Their findings suggested that the ROCK signaling pathway should be considered as a potential therapeutic target for inhibiting lung cancer development, as ROCK action is diffuse and its activation can promote multiple hallmarks of cancer.

\section{Other druggable targets of lung cancer}

Identifying the genetic aberrations of lung cancer, such as KRAS and EGFR mutations is important in tailoring the appropriate therapy for the disease. NSCLC harboring KRAS mutations has been found to be more vulnerable to RhoA inhibitor-induced apoptosis compared to wild-type NSCLC (127). As KRAS mutations are common in lung cancer, occurring in 30\% of adenocarcinoma and 5\% of SCC cases, the inhibition if RhoA appears to be an excellent treatment option for NSCLC $(45,128)$. Furthermore, the KRAS-mutant NSCLC cell line is also vulnerable to a combination of drug pairs that inhibit polo-like kinase 1 (PLK1), a synthetic lethal partner of Ras oncogene, and ROCK that exhibit marked apoptosis induction and colony form inhibition (45). Another common 
Table I. Studies on kinase-targeting ROCK inhibition in lung cancer.

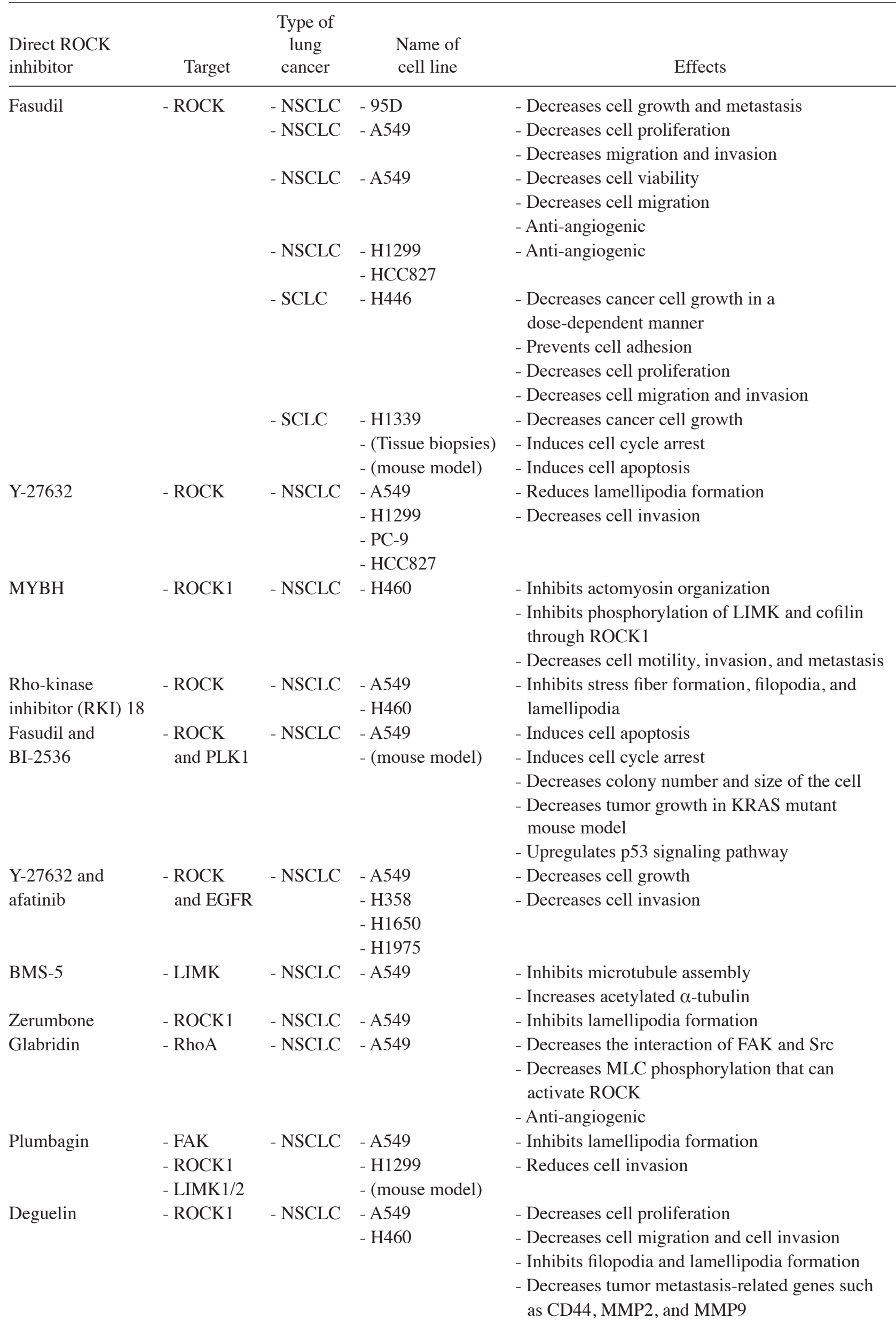

(Refs.) 
Table I. Continued.

\begin{tabular}{|c|c|c|c|c|c|}
\hline $\begin{array}{l}\text { Direct ROCK } \\
\text { inhibitor }\end{array}$ & Target & $\begin{array}{l}\text { Type of } \\
\text { lung } \\
\text { cancer }\end{array}$ & $\begin{array}{l}\text { Name of } \\
\text { cell line }\end{array}$ & Effects & (Refs.) \\
\hline B-Escin & - RhoA & - NSCLC & $\begin{array}{l}\text { - H460 } \\
\text { - (mouse model) }\end{array}$ & $\begin{array}{l}\text { - Inhibits tobacco carcinogen-induced lung tumor } \\
\text { formation by modulating RhoA/Rock signaling }\end{array}$ & $(108)$ \\
\hline XAP & - RhoC & - NSCLC & - A549 & $\begin{array}{l}\text { - Decreases cell proliferation } \\
\text { - Decreases cell migration and invasion } \\
\text { - Reduces CCR5 chemokine receptor expression }\end{array}$ & $(102)$ \\
\hline OXA-06 & - ROCK & - NSCLC & $\begin{array}{l}\text { - A549 } \\
\text { - H1299 } \\
\text { - H23 } \\
\text { - H358 } \\
\text { - H1703 }\end{array}$ & $\begin{array}{l}\text { - Induces cell cycle arrest } \\
\text { - Decreases anchorage-independent growth and } \\
\text { cell invasion }\end{array}$ & (15) \\
\hline shRNA & $\begin{array}{l}\text { - ROCK1 } \\
\text { and PTEN }\end{array}$ & - NSCLC & $\begin{array}{l}\text { - A549 } \\
\text { - H1299 } \\
\text { - H226 } \\
\text { - SK-MES-1 }\end{array}$ & - Decreases cell migration and invasion & (37) \\
\hline & - RhoC & - NSCLC & - A549 & - Decreases EMT induced by TGF- $\beta 1$ & $(85)$ \\
\hline \multirow[t]{2}{*}{ siRNA } & - ROCK & - NSCLC & - H1299 & $\begin{array}{l}\text { - Decreases cell growth with a near-complete } \\
\text { suppression of colony formation }\end{array}$ & $(15)$ \\
\hline & - ROCK1 & - NSCLC & - A549 & $\begin{array}{l}\text { - Decreases cell viability } \\
\text { - Induces cell apoptosis } \\
\text { - Decreases cell proliferation }\end{array}$ & $(67)$ \\
\hline MicroRNA-335-5p & - ROCK1 & - NSCLC & $\begin{array}{l}\text { - A549 } \\
\text { - SPC-A1 } \\
\text { - (Tissue biopsies) }\end{array}$ & $\begin{array}{l}\text { - Decreases TGF- } \beta 1 \text {-induced EMT } \\
\text { - Decreases cell migration and invasion }\end{array}$ & $(19)$ \\
\hline MicroRNA-186 & - ROCK1 & - NSCLC & $\begin{array}{l}\text { - A549 } \\
\text { - H1299 } \\
\text { - H358 } \\
\text { - H157 } \\
\text { - (Tissue biopsies) }\end{array}$ & $\begin{array}{l}\text { - Decreases proliferation } \\
\text { - Decreases cell invasion and migration }\end{array}$ & $(20)$ \\
\hline MicroRNA-148a & - ROCK1 & - NSCLC & $\begin{array}{l}\text { - A549 } \\
\text { - H1299 } \\
\text { - (Tissue biopsies) }\end{array}$ & $\begin{array}{l}\text { - Decreases EMT } \\
\text { - Decreases cell invasion }\end{array}$ & (116) \\
\hline MicroRNA-101 & - ROCK2 & - NSCLC & $\begin{array}{l}\text { - A549 } \\
\text { - NCI-460 } \\
\text { - NCI-520 } \\
\text { - NCI-H596 } \\
\text { - (Tissue biopsies) }\end{array}$ & $\begin{array}{l}\text { - Downregulation of miR-101 contributes to } \\
\text { - EMT in cisplatin resistance-NSCCLC } \\
\text { - Low miR-101 expression is associated a with } \\
\text { poor survival time }\end{array}$ & (115) \\
\hline
\end{tabular}

gene aberration that has been studied as a drug target is EGFR mutations, which occur in $39 \%$ of adenocarcinoma and $58 \%$ of the SCC subtype of lung cancer (129). EGFR is a tyrosine kinase that plays an essential role in SCC pathogenesis by dimerizing its receptor (130). Therefore, inhibiting EGFR dimerization can inhibit the pathogenesis, and inhibiting RhoA by using lovastatin has been shown to yield the same effect as an EGFR inhibitor, as RhoA is necessary for EGFR localization and activation (131). Inhibiting EGFR activation can also reduce programmed death-ligand 1 (PD-L1) expression associated with the p-ERK1/2/p-c-Jun pathway (132). Reducing PD-1 and its interaction with the ligand is important in restoring the proliferation of T-cells and promoting the cytotoxic activity of immune cells to cancer cells (133). Importantly, an increased PD-L1 expression has been reported to be associated with EGFR mutations $(134,135)$ and is currently the only approved biomarker for NSCLC immune checkpoint inhibitors (136).

Targeting proteins that regulate the ROCK signaling pathway has also been suggested to yield promising results. Osteopontin (OPN), a major non-collagenous bone matrix protein, has been found to be responsible for activating ROCK1, and to subsequently increase LIMK and cofilin phosphorylation in NSCLC cell lines, thereby promoting cancer cell migration and invasion (103). It is suggested that 
Table II. Studies on non-kinase-targeting ROCK inhibition in lung cancer.

\begin{tabular}{|c|c|c|c|c|c|}
\hline $\begin{array}{l}\text { Indirect ROCK } \\
\text { inhibitor }\end{array}$ & Target & $\begin{array}{c}\text { Type of } \\
\text { lung cancer }\end{array}$ & Name of cell line & Effects & (Refs.) \\
\hline KRT14 lentivirus & - KRT14 & - NSCLC & $\begin{array}{l}\text { - A549 } \\
\text { - H1975 } \\
\text { - (mouse model) }\end{array}$ & $\begin{array}{l}\text { KRT14 depletion reduces: } \\
\text { - ROCK1 expression } \\
\text { - Cell migration and invasion }\end{array}$ & (120) \\
\hline DEK siRNA & - DEK & - NSCLC & $\begin{array}{l}\text { - A549 } \\
\text { - H1299 } \\
\text { - (Tissue biopsies) }\end{array}$ & $\begin{array}{l}\text { DEK depletion reduces: } \\
\text { - RhoA expression } \\
\text { - Cell proliferation } \\
\text { - Cell migration }\end{array}$ & (73) \\
\hline CHD4 siRNA & - CHD4 & - NSCLC & $\begin{array}{l}\text { - A549 } \\
\text { - H1299 } \\
\text { - (Tissue biopsies) } \\
\text { - (mouse model) }\end{array}$ & $\begin{array}{l}\text { CHD4 depletion reduces: } \\
\text { - RhoA, ROCK, phosphor-myosin expression } \\
\text { - Cell proliferation } \\
\text { - Cell migration } \\
\text { - Cell growth }\end{array}$ & (74) \\
\hline lncNORAD siRNA & - IncNORAD & - NSCLC & $\begin{array}{l}\text { - A549 } \\
\text { - (mouse model) }\end{array}$ & $\begin{array}{l}\text { lncNORAD depletion reduces: } \\
\text { - RhoA/ROCK expression } \\
\text { - Cell proliferation } \\
\text { - Cell migration and invasion }\end{array}$ & (121) \\
\hline
\end{tabular}

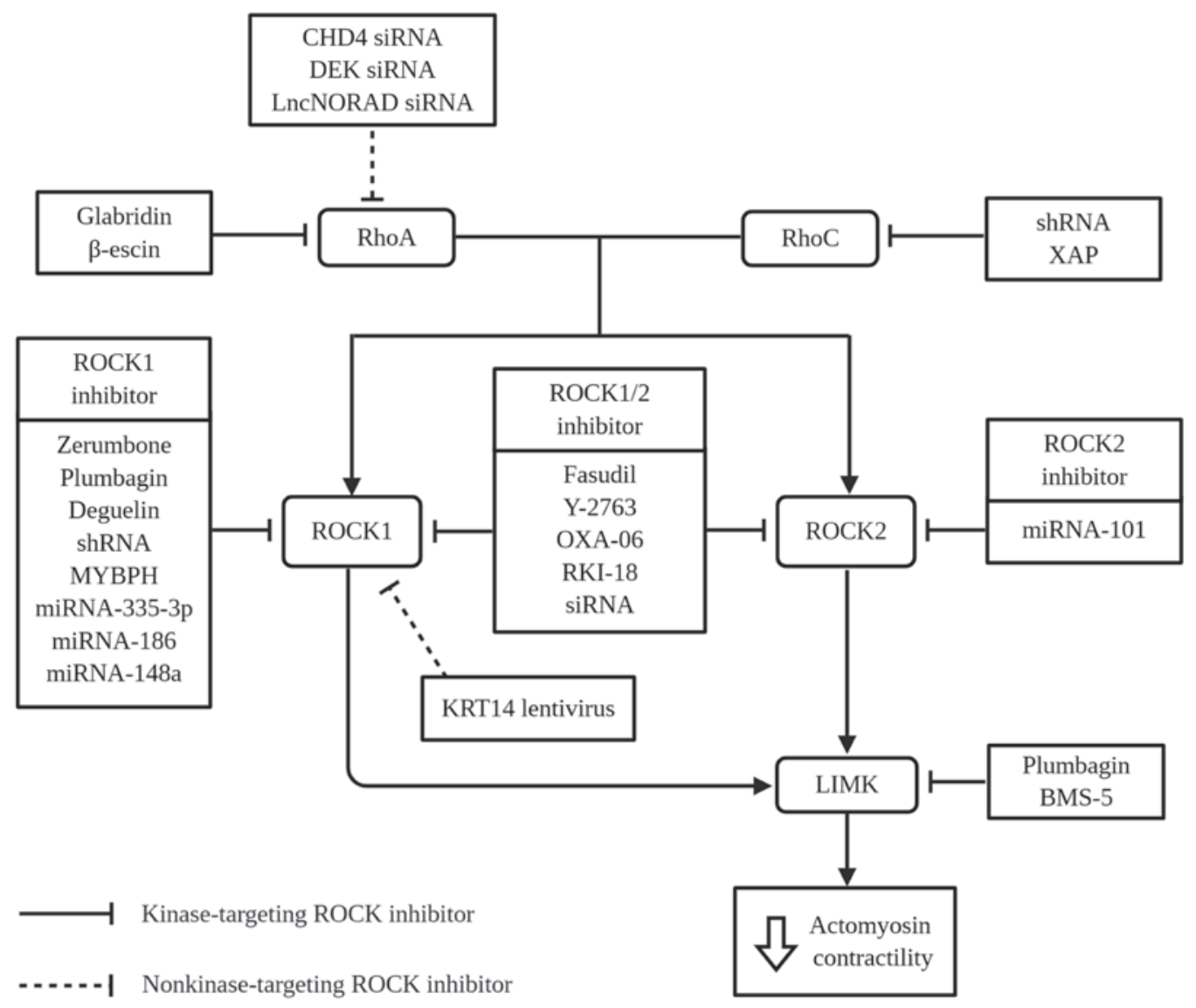

Figure 3. Targets of kinase-targeting ROCK inhibitors and non-kinase-targeting ROCK inhibitors. ROCK, Rho-associated kinase; LIMK, Lim kinase.

OPN is a worthy target as its inhibition can significantly reduce the tumor weight and volume of NSCLC as studied by Cho et al (137). In addition, OPN can reduce lamellipodia formation and actin polymerization via the ROCK signaling pathway following suppression with zerumbone and plumbagin, respectively $(46,80)$. Since OPN plays an essential role in mediating tumor-stroma interaction and contributes to tumor growth and metastasis (138), targeting OPN may 
hold promise for the prevention of lung cancer metastasis. In addition, caveolin-1 (CAV1), an ECM-associated oncogenic membrane protein that can activate the ROCK signaling pathway, may also be a potential druggable target. High levels of stromal CAV1 have been identified in various types of cancer, including lung cancer $(139,140)$ and its interactions with Rho-GTPases have been demonstrated to promote metastasis through Src, Ras and Erk activation (141). This interaction promotes cell migration and invasion by regulating CAV1 tyrosine phosphorylation, which can lead to the regulation of focal adhesion dynamics (142).

\section{Conclusion and future direction}

The treatment of lung cancer has improved substantially over the years, involving various strategies and modalities, such as surgery, radiotherapy, chemotherapy, immunotherapy and molecular-targeted therapy (143). The search for a suitable target candidate to treat lung cancer is still ongoing. Herein, the ROCK signaling pathway is suggested as one of the potential targets that can be utilized for the treatment of lung cancer, since its inhibition has resulted in promising outcomes to reduce cancer cell proliferation, migration, and invasion in pre-clinical studies. Repurposing the use of already licensed drugs, such as fasudil for the treatment of lung cancer is a good start, as it provides a rapid translation of pre-clinical data into effective therapies for lung cancer patients. However, the use of fasudil is still associated with certain drawbacks, such as the off-target effect. On the other hand, other novel compounds may have insufficient efficacy apart from the concerns of side-effects and the selective binding of ROCK inhibitors, as the ROCK signaling pathway also plays an essential role in normal cell homeostasis. Nevertheless, the expression of ROCK in cancer is higher if compared to normal cells or tissues; thus, the use of ROCK inhibitors in cancerous and normal cells or tissues may yield different outcomes in term of expression following treatment. Specific pathway inhibition, limited to cancer cells, is preferable to prevent undesirable side-effects caused by current chemotherapeutic drugs. Obtaining a range of effective doses without causing adverse effects in patients is also another challenge that requires a comprehensive analysis of safety, efficacy and toxicity to be made. The majority of the ROCK and lung cancer studies were found to be performed in vitro only, while there is a lack of in vivo studies or the use of tissue biopsies from patients with lung cancer. Therefore, further research should also employ these more complex settings to fully elucidate the mechanisms of the ROCK signaling pathway in lung cancer.

To date, to the best of our knowledge, no single inhibitor targeting the ROCK signaling pathway has been approved for use in clinical trials against lung cancer. Nevertheless, defactinib, a drug that can inhibit FAK, a mechanosensor that can detect changes in the ECM and activate ROCK, has been tested in a clinical trial for the treatment of KRAS mutant NSCLC. However, defactinib has been shown to only yield modest and contrasting results from pre-clinical studies (144). This may be due to the insufficient efficacy and it being an unspecific target of FAK inhibitor. Therefore, it is suggested that the targeting of ROCK should be performed to yield a more profound impact in regulating cellular phenotypes, as discussed herein, thus treating lung cancer. A combination of agents in the treatment of lung cancer should also be considered in future research, as supported by better outcomes in pre-clinical studies targeting ROCK with EFGR or PLK1 $(45,104)$. Moreover, an agent that can affect multiple oncogenic pathways and fine-tuning treatment strategies based on molecular aberrations can provide more effective treatment strategies, since cancer is highly adaptive and can acquire resistance rapidly $(145,146)$. Targeting ROCK can also help to solve several issues, such as drug resistance seen in hypoxic tumors. According to Murakami et al (147), gefitinib was found to be ineffective in hypoxic EGFR mutation-positive NSCLC due to a vascular inadequacy that dampens the bioavailability of the drug in the target area. Therefore, targeting ROCK along with gefitinib can help in restoring the role of the blood vessel to deliver oxygen and increase the drug bioavailability. Taken together, the ROCK signaling pathway plays a critical role in the carcinogenesis of lung cancer, and is therefore suggested as a potential therapeutic target in the treatment of lung cancer. Further in-depth research is urgently required to enhance our understanding of this pathway, and further attempts should be made to elucidate the biological mechanisms between ROCK and lung cancer.

\section{Acknowledgements}

Not applicable.

\section{Funding}

The present study was supported by the Ministry of Higher Education (grant no. FRGS/1/2018/SKK06/UKM/03/1).

\section{Availability of data and materials}

Not applicable.

\section{Authors' contributions}

MAZ and SFM contributed to the conceptualization, drafting and writing of the manuscript. SFM, EWC, NFR and GTS provided substantial contributions to the finalization, correction and critical reviewing of the manuscript. All authors read and approved the final manuscript.

\section{Ethics approval and consent to participate}

Not applicable.

\section{Patient consent for publication}

Not applicable.

\section{Competing interests}

The authors declare that they have no competing interests.

\section{References}

1. World Health Organization (WHO): Cancer, 2019. 
2. Remen T, Pintos J, Abrahamowicz M and Siemiatycki J: Risk of lung cancer in relation to various metrics of smoking history: A case-control study in Montreal. BMC Cancer 18: 1275, 2018.

3. Dela Cruz CS, Tanoue LT and Matthay RA: Lung cancer: Epidemiology, etiology, and prevention. Clin Chest Med 32: 605-644, 2011.

4. Perez-Moreno P, Brambilla E, Thomas R and Soria JC: Squamous cell carcinoma of the lung: Molecular subtypes and therapeutic opportunities. Clin Cancer Res 18: 2443-2451, 2012.

5. Gandara DR, Hammerman PS, Sos ML, Lara PN Jr and Hirsch FR: Squamous cell lung cancer: From tumor genomics to cancer therapeutics. Clin Cancer Res 21: 2236-2243, 2015.

6. Siegel R, Naishadham D and Jemal A: Cancer statistics, 2013. CA Cancer J Clin 63: 11-30, 2013

7. Sosa Iglesias V, Giuranno L, Dubois LJ, Theys J and Vooijs M: Drug resistance in non-small cell lung cancer: A potential for NOTCH targeting? Front Oncol 8: 267, 2018.

8. Gentzler RD and Johnson ML: Complex decisions for first-line and maintenance treatment of advanced wild-type non-small cell lung cancer. Oncologist 20: 299-306, 2015.

9. Baxevanos P and Mountzios G: Novel chemotherapy regimens for advanced lung cancer: Have we reached a plateau? Ann Transl Med 6: 139, 2018.

10. Thomas A, Rajan A and Giaccone G: Tyrosine kinase inhibitors in lung cancer. Hematol Oncol Clin North Am 26: 589-605, 2012.

11. Chung $\mathrm{CH}$ : EGFR tyrosine kinase inhibitor therapy for lung cancer treatments and their clinical outcomes: A cohort study in Taiwan. Oncol Lett 18: 6090-6100, 2019.

12. Peng Y, Chen Z, Chen Y, Li S, Jiang Y, Yang H, Wu C, You F, Zheng C, Zhu J, et al: ROCK isoforms differentially modulate cancer cell motility by mechanosensing the substrate stiffness. Acta Biomater 88: 86-101, 2019.

13. Masre SF, Rath N, Olson MF and Greenhalgh DA: ROCK2/ras ${ }^{\mathrm{H}}$ co-operation induces malignant conversion via p53 loss, elevated $\mathrm{NF}-\mathrm{KB}$ and tenascin $\mathrm{C}$-associated rigidity, but $\mathrm{p} 21$ inhibits ROCK2/NF- $\kappa \mathrm{B}$-mediated progression. Oncogene 36: 2529-2542, 2017.

14. Zheng Y, Xiang L, Chen M and Xiang C: MicroRNA-130a inhibits the proliferation, migration and invasive ability of hepatocellular carcinoma cells by downregulating Rho-kinase 2 . Mol Med Rep 18: 3077-3084, 2018.

15. Vigil D, Kim TY, Plachco A, Garton AJ, Castaldo L, Pachter JA, Dong H, Chen X, Tokar B, Campbell SL and Der CJ: ROCK1 and ROCK 2 are required for non-small cell lung cancer anchorage-independent growth and invasion. Cancer Res 72 5338-5347, 2012

16. Yang X, Zhang Y, Wang S and Shi W: Effect of fasudil on growth, adhesion, invasion, and migration of 95D lung carcinoma cells in vitro. Can J Physiol Pharmacol 88: 874-879, 2010.

17. Zhu F, Zhang Z, Wu G, Li Z, Zhang R, Ren J and Nong L: Rho kinase inhibitor fasudil suppresses migration and invasion though down-regulating the expression of VEGF in lung cancer cell line A549. Med Oncol 28: 565-571, 2011.

18. Huo Z, Su Y, Dong Y, Zheng Y, Zhang Q, Duan Y and Wang G: Rho-kinase inhibition by Fasudil promotes tumor maturation and apoptosis in small-cell lung cancer. Am J Transl Res 12: 4354-4370, 2020.

19. Du W, Tang H, Lei Z, Zhu J, Zeng Y, Liu Z and Huang JA miR-335-5p inhibits TGF- $\beta 1$-induced epithelial-mesenchymal transition in non-small cell lung cancer via ROCK1. Respir Res 20: 225, 2019

20. Cui G, Cui M, Li Y, Liang Y, Li W, Guo H and Zhao S: MiR-186 targets ROCK1 to suppress the growth and metastasis of NSCLC cells. Tumor Biol 35: 8933-8937, 2014

21. Hosono Y, Yamaguchi T, Mizutani E, Yanagisawa K, Arima C, Tomida S, Shimada Y, Hiraoka M, Kato S, Yokoi K, et al: MYBPH, a transcriptional target of TTF-1, inhibits ROCK1, and reduces cell motility and metastasis. EMBO J 31: 481-493, 2012

22. Nakagawa O, Fujisawa K, Ishizaki T, Saito Y, Nakao K and Narumiya S: ROCK-I and ROCK-II, two isoforms of Rho-associated coiled-coil forming protein serine/threonine kinase in mice. FEBS Lett 392: 189-193, 1996.

23. Matsui T, Amano M, Yamamoto T, Chihara K, Nakafuku M, Ito M, Nakano T, Okawa K, Iwamatasu A and Kaibuchi K: Rho-associated kinase, a novel serine/threonine kinase, as a putative target for small GTP binding protein Rho. EMBO J 15: 2208-2216, 1996.

24. Amano M, Ito M, Kimura K, Fukata Y, Chihara K, Nakano T, Matsuura Y and Kaibuchi K: Phosphorylation and activation of myosin by Rho-associated kinase (Rho-kinase). J Biol Chem 271: 20246-20249, 1996
25. Maekawa M, Ishizaki T, Boku S, Watanabe N, Fujita A, Iwamatsu A, Obinata T, Ohashi K, Mizuno K and Narumiya S: Signaling from Rho to the actin cytoskeleton through protein kinases ROCK and LIM-kinase. Science 285: 895-898, 1999.

26. Ohashi K, Nagata K, Maekawa M, Ishizaki T, Narumiya S and Mizuno K: Rho-associated kinase ROCK activates LIM-kinase 1 by phosphorylation at threonine 508 within the activation loop. J Biol Chem 275: 3577-3582, 2000.

27. Hoon JL, Tan MH and Koh CG: The regulation of cellular responses to mechanical cues by Rho GTPases. Cells 5: 17, 2016.

28. Julian L and Olson MF: Rho-associated coiled-coil containing kinases (ROCK), structure, regulation, and functions. Small GTPases 5: e29846, 2014

29. Riento K and Ridley AJ: Rocks: Multifunctional kinases in cell behaviour. Nat Rev Mol Cell Biol 4: 446-456, 2003.

30. Rath $\mathrm{N}$ and Olson MF: Rho-associated kinases in tumorigenesis: Re-considering ROCK inhibition for cancer therapy. EMBO Rep 13: 900-908, 2012.

31. Samuel MS, Lopez JI, McGhee EJ, Croft DR, Starchan D, Timpson P, Munro J, Schröder E, Zhou J, Brunton VG, et al: Actomyosin-mediated cellular tension drives increased tissue stiffness and $\beta$-catenin activation to induce epidermal hyperplasia and tumor growth. Cancer Cell 19: 776-791, 2011

32. Chow W, Amaya CN, Rains S, Chow M, Dickerson EB and Bryan BA: Growth attenuation of cutaneous angiosarcoma with propranolol-mediated $\beta$-blockade. JAMA Dermatol 151: $1226-1229,2015$

33. Ishizaki T, Maekawa M, Fujisawa K, Okawa K, Iwamatsu A, Fujita A, Watanabe N, Saito Y, Kakizuka A, Morii N and Narumiya S: The small GTP-binding protein Rho binds to and activates a $160 \mathrm{kDa} \mathrm{Ser} / \mathrm{Thr}$ protein kinase homologous to myotonic dystrophy kinase. EMBO J 15: 1885-1893, 1996.

34. Kümper S, Mardakheh FK, McCarthy A, Yeo M, Stamp GW, Paul A, Worboys J, Sadok A, Jørgensen C, Guichard S and Marshall CJ: Rho-associated kinase (ROCK) function is essential for cell cycle progression, senescence and tumorigenesis. Elife 5: e12994, 2016.

35. Chevrier V, Piel M, Collomb N, Saoudi Y, Frank R, Paintrand M, Narumiya S, Bornens M and Job D: The Rho-associated protein kinase p160ROCK is required for centrosome positioning. J Cell Biol 157: 807-817, 2002

36. Iizuka M, Kimura K, Wang S, Kato K, Amano M, Kaibuchi K and Mizoguchi A: Distinct distribution and localization of Rho-kinase in mouse epithelial, muscle and neural tissues. Cell Struct Funct 37: 155-175, 2012.

37. Hu C, Zhou H, Liu Y, Huang J, Liu W, Zhang Q, Tang Q, Sheng F, $\mathrm{Li} \mathrm{G}$ and Zhang R: ROCK1 promotes migration and invasion of non-small-cell lung cancer cells through the PTEN/PI3K/FAK pathway. Int J Oncol 55: 833-844, 2019.

38. Liu X, Choy E, Hornicek FJ, Yang S, Yang C, Harmon D, Mankin $\mathrm{H}$ and Duan Z: ROCK1 as a potential therapeutic target in osteosarcoma. J Orthop Res 29: 1259-1266, 2011.

39. Vieira GM, Roberto GM, Lira RC, Engel EE, Tone LG and Brassesco MS: Prognostic value and functional role of ROCK2 in pediatric Ewing sarcoma. Oncol Lett 15: 2296-2304, 2018.

40. Zakaria MA, Rajab NF, Chua EW, Selvarajah GT and Masre SF: The roles of tissue rigidity and its underlying mechanisms in promoting tumor growth. Cancer Invest 38: 445-462, 2020.

41. Amaya CN, Mitchell DC and Bryan BA: Rho kinase proteins display aberrant upregulation in vascular tumors and contribute to vascular tumor growth. BMC Cancer 17: 485, 2017

42. Masre SF, Rath N, Olson MF and Greenhalgh DA: Epidermal ROCK2-induces AKT1/GSK3 $\beta / \beta$-catenin, NFKB and dermal tenascin-C; but enhanced differentiation and p53/p21 inhibit papilloma. Carcinogenesis 41: 1409-1420, 2020.

43. Li J, Bharadwaj SS, Guzman G, Vishnubhotla R and Glover SC ROCK I has more accurate prognostic value than met in predicting patient survival in colorectal cancer. Anticancer Res 35: 3267-3273, 2015

44. Kumar MS, Hancock DC, Molina-Arcas M, Steckel M, East P, Diefenbacher M, Armenteros-Monterroso E, Lassailly F, Matthews N, Nye E, et al: The GATA2 transcriptional network is requisite for RAS oncogene-driven non-small cell lung cancer. Cell 149: 642-655, 2012

45. Wang J, Hu K, Guo J, Cheng F, Lv J, Jiang W, Lu W, Liu J, Pang X and Liu M: Suppression of KRas-mutant cancer through the combined inhibition of KRAS with PLK1 and ROCK. Nat Commun 7: 11363, 2016. 
46. Kang CG, Im E, Lee HJ and Lee EO: Plumbagin reduces osteopontin-induced invasion through inhibiting the Rho-associated kinase signaling pathway in A549 cells and suppresses osteopontin-induced lung metastasis in BalB/c mice. Bioorg Med Chem Lett 27: 1914-1918, 2017.

47. Yan SH, Gao HC, Meng HY, Cheng L, Zhe L, Cao GS, Yan WQ and Xin H: Role of Rock 1 protein in non-small cell lung cancer. Biomed Res 28: 2530-2534, 2017.

48. Zhang C, Qin S, Qin L, Liu L, Sun W, Li X, Li N, Wu R and Wang X: Cigarette smoke extract-induced p120-mediated $\mathrm{NF}-\kappa \mathrm{B}$ activation in human epithelial cells is dependent on the RhoA/ROCK pathway. Sci Rep 6: 23131, 2016.

49. Duong-Quy S, Dao P, Hua-Huy T, Guilluy C, Pacaud P and Dinh-Xuan AT: Increased Rho-kinase expression and activity and pulmonary endothelial dysfunction in smokers with normal lung function. Eur Respir J 37: 349-355, 2011.

50. Tan X and Chen M: MYLK and MYL9 expression in non-small cell lung cancer identified by bioinformatics analysis of public expression data. Tumor Biol 35: 12189-12200, 2014.

51. Zhang D, Zhang JY, Dai SD, Liu SL, Liu Y, Tang N and Wang EH: Co-expression of delta-catenin and RhoA is significantly associated with a malignant lung cancer phenotype. Int J Clin Exp Pathol 7: 3724-3732, 2014.

52. Vishnubhotla R, Bharadwaj S, Sun S, Metlushko V and Glover SC: Treatment with Y-27632, a ROCK inhibitor, increases the proinvasive nature of SW620 cells on 3D collagen type 1 matrix. Int J Cell Biol 2012: 259142, 2012.

53. Samuel MS, Rath N, Masre SF, Boyle ST, Greenhalgh DA, KochetkovaM,BrysonS,StevensonDandOlsonMF:Tissue-selective expression of a conditionally-active ROCK2-estrogen receptor fusion protein. Genesis 54: 636-646, 2016.

54. Burgstaller G, Oehrle B, Gerckens M, White ES, Schiller HB and Eickelberg O: The instructive extracellular matrix of the lung: Basic composition and alterations in chronic lung disease. Eur Respir J 50: 1601805, 2017.

55. Xu S, Xu H, Wang W, Li S, Li H, Li T, Zhang W, Yu X and Liu L: The role of collagen in cancer: From bench to bedside. J Transl Med 17: 309, 2019.

56. Galbraith CG, Yamada KM and Sheetz MP: The relationship between force and focal complex development. J Cell Biol 159: 695-705, 2002

57. Wozniak MA, Desai R, Solski PA, Der CJ and Keely PJ ROCK-generated contractility regulates breast epithelial cell differentiation in response to the physical properties of a three-dimensional collagen matrix. J Cell Biol 163: 583-595, 2003

58. Gkretsi V and Stylianopoulos T: Cell adhesion and matrix stiffness : Coordinating cancer cell invasion and metastasis. Front Oncol 8: 145, 2018.

59. Le QT, Chen E, Salim A, Cao H, Kong CS, Whyte R, Donington J, Cannon W, Wakelee H, Tibshirani R, et al: An evaluation of tumor oxygenation and gene expression in patients with early stage non-small cell lung cancers. Clin Cancer Res 12 : $1507-1514,2006$

60. Kataoka Y, Ohshio Y, Teramoto K, Igarashi T, Asai T and Hanaoka J: Hypoxia-induced galectin-3 enhances RhoA function to activate the motility of tumor cells in non-small cell lung cancer. Oncol Rep 41: 853-862, 2019.

61. Gilkes DM, Xiang L, Lee SJ, Chaturvedi P, Hubbi ME, Wirtz D and Semenza GL: Hypoxia-inducible factors mediate coordinated RhoA-ROCK 1 expression and signaling in breast cancer cells. Proc Natl Acad Sci USA 111: E384-E393, 2014.

62. Rofstad EK, Gaustad JV, Egeland TA, Mathiesen B and Galappathi K: Tumors exposed to acute cyclic hypoxic stress show enhanced angiogenesis, perfusion and metastatic dissemination. Int J Cancer 127: 1535-1546, 2010.

63. Xue Y, Wu L, Liu Y, Ma Y, Zhang L, Ma X, Yang Y and Chen J: ENTPD5 induces apoptosis in lung cancer cells via regulating caspase 3 expression. PLoS One 10: e0120046, 2015.

64. Liu D, Mei X, Wang L and Yang X: RhoA inhibits apoptosis and increases proliferation of cultured SPCA1 lung cancer cells. Mo Med Rep 15: 3963-3968, 2017.

65. Radziszewska A, Schroer SA, Choi D, Tajmir P, Radulovich N, Ho JC, Wang L, Liadis N, Hakem R, Tsao MS, et al: Absence of caspase-3 protects pancreatic $\beta$-cells from c-Myc-induced apoptosis without leading to tumor formation. J Biol Chem 284: 10947-10956, 2009.

66. Yang X, Di J, Zhang Y, Zhang S, Lu J, Liu J and Shi W: The Rho-kinase inhibitor inhibits proliferation and metastasis of small cell lung cancer. Biomed Pharmacother 66: 221-227, 2012 .
67. Xin T, Lv W, Liu D, Jing Y and Hu F: ROCK1 knockdown inhibits non-small-cell lung cancer progression by activating the LATS2-JNK signaling pathway. Aging (Albany NY) 12: 12160-12174, 2020

68. Chen W, Li Z, Bai L and Lin Y: NF-kappaB in lung cancer, a carcinogenesis mediator and a prevention and therapy target. Front Biosci (Landmark Ed) 16: 1172-1185, 2011.

69. Orgaz JL, Herraiz C and Sanz-Moreno V: Rho GTPases modulate malignant transformation of tumor cells. Small GTPases 5: e29019, 2014.

70. Kang JH, Jang YS, Lee HJ, Lee CY, Shin DY and Oh SH Inhibition of STAT3 signaling induces apoptosis and suppresses growth of lung cancer: Good and bad. Lab Anim Res 35: 30 , 2019.

71. Gu L, Wang Z, Zuo J, Li H and Zha L: Prognostic significance of $\mathrm{NF}-\kappa \mathrm{B}$ expression in non-small cell lung cancer: A meta-analysis. PLoS One 13: $\mathrm{e}$ 0198223, 2018.

72. Morgensztern D, Campo MJ, Dahlberg SE, Doebele RC, Garon E, Gerber DE, Goldberg SB, Hammerman PS, Heist RS Hensing T, et al: Molecularly targeted therapies in non-small-cell lung cancer annual update 2014. J Thorac Oncol 10 (1 Suppl 1): S1-S63, 2015.

73. Wang J, Sun L, Yang M, Luo W, Gao Y, Liu Z, Qiu X and Wang E: DEK depletion negatively regulates Rho/ROCK/MLC pathway in non-small cell lung cancer. J Histochem Cytochem 61: 510-521, 2013.

74. Xu N, Liu F, Wu S, Ye M, Ge H, Zhang M, Song Y, Tong L, Zhou J and Bai C: CHD4 mediates proliferation and migration of non-small cell lung cancer via the RhoA/ROCK pathway by regulating PHF5A. BMC Cancer 20: 262, 2020.

75. Asnaghi L, Vass WC, Quadri R, Day PM, Qian X, Braverman R, Papageorge AG and Lowry DR: E-cadherin negatively regulates neoplastic growth in non-small cell lung cancer: Role of Rho GTPases. Oncogene 29: 2760-2771, 2010.

76. Croft DR and Olson MF: The Rho GTPase effector ROCK regulates cyclin A, cyclin D1, and p27Kip1 levels by distinct mechanisms. Mol Cell Biol 26: 4612-4627, 2006.

77. Street CA and Bryan BA: Rho kinase proteins-pleiotropic modulators of cell survival and apoptosis. Anticancer Res 31: 3645-3657, 2011.

78. Tang Y, Hu C, Yang H, Cao L, Li Y, Deng P and Huang L: Rnd3 regulates lung cancer cell proliferation through notch signaling. PLoS One 9: e111897, 2014.

79. Amano M, Nakayama M and Kaibuchi K: Rho-Kinase/ROCK: A key regulator of the cytoskeleton and cell polarity. Cytoskeleton (Hoboken) 67: 545-554, 2010

80. Kang CG, Lee HJ, Kim SH and Lee EO: Zerumbone suppresses osteopontin-induced cell invasion through inhibiting the FAK/AKT/ROCK pathway in human non-small cell lung cancer a549 cells. J Nat Prod 79: 156-160, 2016.

81. Zhang Z, Ren JH, Li ZY, Nong L and Wu G: Fasudil inhibits lung carcinoma-conditioned endothelial cell viability and migration. Oncol Rep 27: 1561-1566, 2012.

82. Gandalovičová A, Vomastek T, Rosel D and Brábek J: Cell polarity signaling in the plasticity of cancer cell invasiveness. Oncotarget 7: 25022-25049, 2016

83. Charras G and Paluch E: Blebs lead the way: How to migrate without lamellipodia. Nat Rev Mol cell Biol 9: 730-736, 2008.

84. Mittal V: Epithelial mesenchymal transition in aggressive lung cancers. Adv Exp Med Biol 890: 37-56, 2016.

85. Lu X, Guo H, Chen X, Xiao J, Zou Y, Wang W and Chen Q Effect of RhoC on the epithelial-mesenchymal transition process induced by TGF- $\beta 1$ in lung adenocarcinoma cells. Oncol Rep 36: 3105-3112, 2016

86. Zhang Q, Li X, Li X, Li X and Chen Z: LncRNA H19 promotes epithelial-mesenchymal transition (EMT) by targeting miR-484 in human lung cancer cells. J Cell Biochem 119: 4447-4457, 2018.

87. Gialeli C, Theocharis AD and Karamanos NK: Roles of matrix metalloproteinases in cancer progression and their pharmacological targeting. FEBS J 278: 16-27, 2011.

88. Rundhaug JE: Matrix metalloproteinases and angiogenesis. J Cell Mol Med 9: 267-285, 2005.

89. Huang Y, Song N, Ding Y, Yuan S, Li X, Cai H, Shi H and Luo Y: Pulmonary vascular destabilization in the premetastatic phase facilitates lung metastasis. Cancer Res 69: 7529-7537, 2009.

90. El-Badrawy MK, Yousef AM, Shaalan D and Elsamanoudy AZ: Matrix metalloproteinase-9 expression in lung cancer patients and its relation to serum mmp-9 activity, pathologic type, and prognosis. J Bronchology Interv Pulmonol 21: 327-334, 2014. 
91. Laack E, Scheffler A, Burkholder I, Boeters I, Andritzky B, Schuch G, Görn M, Vohwinkel G, Edler L, Fiedler W and Hossfeld DK: Pretreatment vascular endothelial growth factor (VEGF) and matrix metalloproteinase-9 (MMP-9) serum levels in patients with metastatic non-small cell lung cancer (NSCLC). Lung Cancer 50: 51-58, 2005.

92. Chang YW, Bean RR and Jakobi R: Targeting RhoA/Rho kinase and p21-activated kinase signaling to prevent cancer development and progression. Recent Pat Anticancer Drug Discov 4 110-124, 2009.

93. Paulis YW, Soetekouw PM, Verheul HM, Tjan-Heijnen VC and Griffioen AW: Signalling pathways in vasculogenic mimicry. Biochim Biophys Acta 1806: 18-28, 2010.

94. Xia Y, Cai XY, Fan JQ, Zhang LL, Ren JH, Li ZY, Zhang RG, $\mathrm{Zhu} F$ and $\mathrm{Wu} \mathrm{G}$ : The role of sema4D in vasculogenic mimicry formation in non-small cell lung cancer and the underlying mechanisms. Int J Cancer 144: 2227-2238, 2019.

95. Maniotis AJ, Folberg R, Hess A, Seftor EA, Gardner LM, Pe'er J, Trent JM, Meltzer PS and Hendrix MJ: Vascular channel formation by human melanoma cells in vivo and in vitro: Vasculogenic mimicry. Am J Pathol 155: 739-752, 1999.

96.Lontos K, Adamik J, Tsagianni A, Galson DL, Chirgwin JM and Suvannasankha A: The role of semaphorin 4D in bone remodeling and cancer metastasis. Front Endocrinol (Lausanne) 9: 322,2018

97. Zahra FT, Sajib MS, Ichiyama Y, Akwii RG, Tullar PE, Cobos C, Minchew SA, Doci CL, Zheng Y, Kubota Y, et al: Endothelial RhoA GTPase is essential for in vitro endothelial functions but dispensable for physiological in vivo angiogenesis. Sci Rep 9 11666, 2019.

98. Shibuya M, Suzuki Y, Sugita K, Saito I, Sasaki T, Takakura K, Nagata I, Kikuchi H, Takemae T, Hidaka H, et al: Effect of AT877 on cerebral vasospasm after aneurysmal subarachnoid hemorrhage: Results of a prospective placebo-controlled double-blind trial. J Neurosurg 76: 571-577, 1992.

99. Yang X, Liu Y, Zong Z and Tian D: The Rho kinase inhibitor fasudil inhibits the migratory behaviour of 95-D lung carcinoma cells. Biomed Pharmacother 64: 58-62, 2010.

100. Miyamoto C, Maehata Y, Motohashi K, Ozawa S, Ikoma T, Hidaka K, Wada-Takahashi S, Takahashi SS, Yoshino F, Yoshida A, et al: Fasudil, a Rho kinase inhibitor, suppresses tumor growth by inducing CXCL14/BRAK in head and neck squamous cell carcinoma. Biomed Res 35: 381-388, 2014.

101. Xia Y, Cai XY, Fan JQ, Zhang LL, Ren JH, Chen J,LiZY,Zhang RG, Zhu F and Wu G: Rho kinase inhibitor fasudil suppresses the vasculogenic mimicry of B16 mouse melanoma cells both in vitro and in vivo. Mol Cancer Ther 14: 1582-1590, 2015.

102. Lin SS, Li FF, Sun L, Fan W, Gu M, Zhang LY, Qin S and Yuan ST: Marsdenia tenacissima extract suppresses A549 cell migration through regulation of CCR5-CCL5 axis, Rho C, and phosphorylated FAK. Chin J Nat Med 14: 203-209, 2016.

103. Kang CG, Han HJ, Lee HJ, Kim SH and Lee EO: Rho-associated kinase signaling is required for osteopontin-induced cell invasion through inactivating cofilin in human non-small cell lung cancer cell lines. Bioorganic Med Chem Lett 25: 1956-1960, 2015.

104. Umelo IA, Wever OD, Kronenberger P, Noor A, Teugels E, Chen $G$, Bracke $M$ and Grève JD: Combined inhibition of rho-associated protein kinase and EGFR suppresses the invasive phenotype in EGFR-dependent lung cancer cells. Lung Cancer 90: 167-174, 2015.

105. Mardilovich K, Baugh M, Crighton D, Kowalczyk D, Gabrielsen M, Munro J, Croft DR, Lourenco F, James D, Kalna G, et al: LIM kinase inhibitors disrupt mitotic microtubule organization and impair tumor cell proliferation. Oncotarget 6: 38469-38486, 2015

106. Tsai YM, Yang CJ, Hsu YL, Wu LY, Tsai YC, Hung JY, Lien CT, Huang MS and Kuo PL: Glabridin inhibits migration, invasion, and angiogenesis of human non-small cell lung cancer A549 cells by inhibiting the FAK/Rho signaling pathway. Integr Cancer Ther 10: 341-349, 2011.

107. Zhao H, Jiao Y and Zhang Z: Deguelin inhibits the migration and invasion of lung cancer A549 and $\mathrm{H} 460$ cells via regulating actin cytoskeleton rearrangement. Int J Clin Exp Pathol 8 15582-15590, 2015

108. Patlolla JM, Qian L, Biddick L, Zhang Y, Desai D, Amin S, Lightfoot $S$ and Rao CV: $\beta$-Escin inhibits NNK-induced lung adenocarcinoma and ALDH1A1 and RhoA/Rock expression in $\mathrm{A} / \mathrm{J}$ mice and growth of $\mathrm{H} 460$ human lung cancer cells. Cancer Prev Res (Phila) 6: 1140-1149, 2013.
109. Aung TN, Qu Z, Kortschak RD and Adelson DL: Understanding the effectiveness of natural compound mixtures in cancer through their molecular mode of action. Int J Mol Sci 18: 656, 2017.

110. Surien O, Ghazali AR and Masre SF: Lung cancers and the roles of natural compounds as potential chemotherapeutic and chemopreventive agents. Biomed Pharmacol J 12: 85-98, 2019.

111. Davies SP, Reddy H, Caivano M and Cohen P: Specificity and mechanism of action of some commonly used protein kinase inhibitors Stephen. Biochem J 351: 95-105, 2000.

112. Patel RA, Liu Y, Wang B, Li R and Sebti SM: Identification of novel ROCK inhibitors with anti-migratory and anti-invasive activities. Oncogene 33: 550-555, 2014.

113. Zhang B, Pan X, Cobb GP and Anderson TA: MicroRNAs as oncogenes and tumor suppressors. Dev Biol 302: 1-12, 2007.

114. Iqbal MA, Arora S, Prakasam G, Calin GA and Syed MA: MicroRNA in lung cancer: Role, mechanisms, pathways and therapeutic relevance. Mol Aspects Med 70: 3-20, 2019.

115. Ye Z, Yin S, Su Z, Bai M, Zhang H, Hei Z and Cai S: Downregulation of miR-101 contributes to epithelial-mesenchymal transition in cisplatin resistance of NSCLC cells by targeting ROCK2. Oncotarget 7: 37524-37535, 2016.

116. Li J, Song Y, Wang Y, Luo J and Yu W: MicroRNA-148a suppresses epithelial-to-mesenchymal transition by targeting ROCK1 in non-small cell lung cancer cells. Mol Cell Biochem 380: 277-282, 2013.

117. Yang M, Shen H, Qiu C, Ni Y, Wang L, Dong W, Liao Y and Du J: High expression of miR-21 and miR-155 predicts recurrence and unfavourable survival in non-small cell lung cancer. Eur J Cancer 49: 604-615, 2013

118. Wu C, Cao Y, He Z, He J, Hu C, Duan H and Jiang J: Serum levels of miR-19b and miR-146a as prognostic biomarkers for non-small cell lung cancer. Tohoku J Exp Med 232: 85-95, 2014.

119. Rodriguez-Hernandez I, Cantelli G, Bruce F and Sanz-Moreno V: Rho, ROCK and actomyosin contractility in metastasis as drug targets. F1000Res 5: F1000 Faculty Rev-783, 2016.

120. Wang X, Han L, Shan S, Sun Y and Mao Y: KRT14 promoting invasion and migration of lung cancer cells through ROCK-1 signaling pathway. Int J Clin Exp Pathol 10: 795-803, 2017.

121. Wu Y, Shen QW, Niu YX, Chen XY, Liu HW and Shen XY: LncNORAD interference inhibits tumor growth and lung cancer cell proliferation, invasion and migration by down-regulating CXCR4 to suppress RhoA/ROCK signaling pathway. Eur Rev Med Pharmacol Sci 24: 5446-5455, 2020.

122. Whatcott CJ, Ng S, Barrett MT, Hostetter G, Von Hoff DD and Han H: Inhibition of ROCK1 kinase modulates both tumor cells and stromal fibroblasts in pancreatic cancer. PLoS One 12: e0183871, 2017.

123. Shin JY, Kim Y Il, Cho SJ, Lee MK, Kook MC, Lee JH, Lee SS, Ashktorab H, Smoot DT, Ryu KW, et al: MicroRNA 135a suppresses lymph node metastasis through down-regulation of ROCK1 in early gastric cancer. PLoS One 9: e85205, 2014

124. Zhang R, Li G, Zhang Q, Tang Q, Huang J, Hu C, Liu Y, Wang Q, Liu W, Gao N and Zhou S: Hirsutine induces mPTP-dependent apoptosis through ROCK1/PTEN/PI3K/GSK3 $\beta$ pathway in human lung cancer cells. Cell Death Dis 9: 598, 2018.

125. Lin L, Li M, Lin L, Xu X, Jiang G and Wu L: FPPS mediates TGF- $\beta 1$-induced non-small cell lung cancer cell invasion and the EMT process via the RhoA/Rock1 pathway. Biochem Biophys Res Commun 496: 536-541, 2018.

126. Ishizaki T, Uehata M, Tamechika I, Keel J, Nonomura K, Maekawa M and Narumiya S: Pharmacological properties of Y-27632, a specific inhibitor of rho-associated kinases. Mol Pharmacol 57: 976-983, 2000.

127. Konstantinidou G, Ramadori G, Torti F, Kangasniemi K, Ramirez RE, Cai Y, Behrens C, Dellinger MT, Brekken RA, Wistuba II, et al: RHOA-FAK is a required signaling axis for the maintenance of KRAS-driven lung adenocarcinomas. Cancer Discov 3: 444-457, 2013.

128. Tomasini P, Walia P, Labbe C, Jao K and Leighl NB: Targeting the KRAS pathway in non-small cell lung cancer. Oncologist 21: 1450-1460, 2016.

129. Korpanty GJ, Graham DM, Vincent MD and Leighl NB: Biomarkers that currently effect clinical practice in lung cancer: EGFR, ALK, MET, ROS-1 and KRAS. Front Oncol 4: 204, 2014.

130. Nicholson RI, Gee JM and Harper ME: EGFR and cancer prognosis. Eur J Cancer 37 (Suppl 4): S9-S15, 2001.

131. Zhao TT, Le Francois BG, Goss G, Ding K, Bradbury PA and Dimitroulakos J: Lovastatin inhibits EGFR dimerization and AKT activation in squamous cell carcinoma cells: Potential regulation by targeting rho proteins. Oncogene 29: 4682-4692, 2010. 
132. Chen N, Fang W, Zhan J, Hong S, Tang Y, Kang S, Zhang Y, He X, Zhou T, Qin T, et al: Upregulation of PD-L1 by EGFR activation mediates the immune escape in EGFR-driven NSCLC: Implication for optional immune targeted therapy for NSCLC patients with EGFR mutation. J Thorac Oncol 10: 910-923, 2015.

133. Zitvogel L and Kroemer G: Targeting PD-1/PD-L1 interactions for cancer immunotherapy. Oncoimmunology 1: 1223-1225, 2012.

134. Azuma K, Ota K, Kawahara A, Hattori S, Iwama E, Harada T, Matsumoto K, Takayama K, Takamori S, Kage M, et al: Association of PD-L1 overexpression with activating EGFR mutations in surgically resected nonsmall-cell lung cancer. Ann Oncol 25: 1935-1940, 2014.

135. Zhang M, Li G, Wang Y, Wang Y, Zhao S, Haihong P, Zhao H and Wang Y: PD-L1 Expression in lung cancer and its correlation with driver mutations: A meta-analysis. Sci Rep 7: 10255, 2017.

136. Kim H and Chung JH: PD-L1 testing in non-small cell lung cancer: Past, present, and future. J Pathol Transl Med 53: 199-206, 2019.

137. Cho WY, Hong SH, Singh B, Islam MA, Lee S, Lee AY, Gankhuyag N, Kim JE, Yu KN, Kim KH, et al: Suppression of tumor growth in lung cancer xenograft model mice by poly(sorbitol-co-PEI)-mediated delivery of osteopontin siRNA. Eur J Pharm Biopharm 94: 450-462, 2015.

138. Zhao H, Chen Q, Alam A, Cui J, Suen KC, Soo AP, Eguchi S, $\mathrm{Gu} \mathrm{J}$ and Ma D: The role of osteopontin in the progression of solid organ tumour. Cell Death Dis 9: 356, 2018.

139. Nwosu ZC, Ebert MP, Dooley S and Meyer C: Caveolin-1 in the regulation of cell metabolism: A cancer perspective. Mol Cancer 15: 71, 2016.

140. Joshi B, Strugnell SS, Goetz JG, Kojic LD, Cox ME, Griffith OL, Chan SK, Jones SJ, Leung SP, Masoudi H, et al: Phosphorylated caveolin-1 regulates Rho/ROCK-dependent focal adhesion dynamics and tumor cell migration and invasion. Cancer Res 68: 8210-8220, 2008
141. Arpaia E, Blaser H, Quintela-Fandino M, Duncan G, Leong HS, Ablack A, Nambiar SC, Lind EF, Silvester J, Fleming CK, et al: The interaction between caveolin-1 and Rho-GTPases promotes metastasis by controlling the expression of alpha5-integrin and the activation of Src, Ras and Erk. Oncogene 31: 884-896, 2012.

142. Urra H, Torres VA, Ortiz RJ, Lobos L, Díaz MI, Díaz N, Härtel S, Leyton L and Quest AF: Caveolin-1-enhanced motility and focal adhesion turnover require Tyrosine-14 but not accumulation to the rear in metastatic cancer cells. PLoS One 7: e33085, 2012.

143. Reck M and Rabe KF: Precision diagnosis and treatment for advanced non-small-cell lung cancer. N Engl J Med 377: 849-861, 2017.

144. Gerber DE, Camidge DR, Morgensztern D, Cetnar J, Kelly RJ, Ramalingam SS, Spigel DR, Jeong W, Scaglioni PP, Zhang S, et al: Phase 2 study of the focal adhesion kinase inhibitor defactinib (VS-6063) in previously treated advanced KRAS mutant non-small cell lung cancer. Lung Cancer 139: 60-67, 2020

145. Hanahan D: Rethinking the war on cancer. Lancet 383: 558-563, 2014.

146. Malone ER, Oliva M, Sabatini PJB, Stockley TL and Siu LL: Molecular profiling for precision cancer therapies. Genome Med 12: 8, 2020.

147. Murakami A, Takahashi F, Nurwidya F, Kobayashi I, Minakata K, Hashimoto M, Nara T, Kato M, Tajima K, Shimada N, et al: Hypoxia increases gefitinib-resistant lung cancer stem cells through the activation of insulin-like growth factor 1 receptor. PLoS One 9: e86459, 2014 